\title{
Environmental Protection Awareness Using Biological Learning Packets
}

\author{
Maria Eva E. Diongco, Ed. D. ${ }^{\text {a,b }}$, Marie Ann S.Gonzales ${ }^{\mathrm{b}}$, and Sanlet B. Llames ${ }^{\mathrm{c} *}$ \\ amariaevadiongco@lspu.edu.ph \\ ${ }^{b}$ Laguna State Polytechnic University, College of Teacher Education-Graduate Studies \& Applied Research, Laguna, 4009 Philippines \\ ${ }^{c}$ Department of Education, Division of Laguna, 4009 Philippines
}

\begin{abstract}
This study aimed to develop and assess biological packets of learning in environmental protection awareness for grade 9 students. Fifty (50) Science teachers from the 4th District in the Division of Laguna assessed the content and acceptability of the module. Finding the weighted mean and standard deviation, frequency, percentage and dependent (related) samples t-test were used. The teacher assessment on the components of the module got the overall mean of 4.49 and SD of 0.56 marked the developed module as Strongly Agree and interpreted as Excellent. In terms of the acceptability, the analysis exhibited that the module was Highly Acceptable with an overall mean of 4.52 and standard deviation of 0.56. Analysis shown that the mean score of the pre-test 7.39 and SD of 1.62 was initially Fair, while the post-test got a mean value of 18.85 and SD of 2.66 that was verbally interpreted as Very Satisfactory. It was revealed in the computed $t$-value of 26.43 was greater that the critical value of 1.98 , therefore rejecting the null hypothesis. Based on the findings, the developed biological learning packets was highly acceptable and was found to be an effective teaching tool. Finally, results of the study suggest to make use of the module which is effective in the enhancement of the students environmental protection awareness.
\end{abstract}

Published by IJRP.ORG. Selection and/or peer-review under responsibility of International Journal of Research Publications (IJRP.ORG)

\subsubsection{Keywords: biological packets; environmental respect; environmental protection}

\section{Introduction}

Global warming has become the fundamental issues globally since it impacts the whole planet and it slowly submerges our world every minute. The Philippines has experienced from low stress typhoons which has intensified into super typhoons with some occurrence of tornadoes and monsoon rain that caused flash floods (Datukon, 2016). Other occurrences such as increased health risk or drought which threatens agriculture, even the endangerment of prominent species prompt the government, private sectors and the civil society to take action about the critical matter. Since then, programs and projects have been created to preserve and protect natural resources, but with the condition that the environment is encountering right now, it takes more than just plans and agendas (Climate Reality Project, 2016). With this, world educators and environmentalist have directionally identified that the solution to this crisis require an environmental 
awareness and understanding which should be intensely embedded in the education system (Medallon \& Gallardo, 2014).

Due to the great danger brought by global warming, every individual especially the youth need to take part in the preservation and conservation of the environment. The educational institutions could be tapped in promoting environmental protection awareness; thus conveying ethical values in the minds of the youth (Maseret, 2016).

\subsection{Purpose of the Study}

The purpose of the study is to develop and assess a module in Biology for Grade 9 students focusing on environmental protection awareness.

\subsection{Literature Review}

The Philipines is facing environmental problems such as pollution, deforestation, landslide, climate change and global warming. Battling global warming could simply start by educating the community. The active involvement of every individual in taking good care of the environment and it starts with environmental protection awareness which must include both the cognitive and affective components (Climate Reality Project (2016).

Environmental awareness maybe increased through the evaluation of human activities, consumption patterns and the general way of life (Takala, 2007). Environmental Education is the method of developing awareness, knowledge and concern to the environment for the benefit of the next generations (De Regla, 2015). Therefore, numerous studies on environment protection must be given emphasis to attain a sustainable healthy environment (Garcia \& Luansing, 2016).

With the aim of developing environmental protection awareness, instructional materials such as learning modules are very essential tools. It sets a structured path so that learners can effectively learn to understand the first topics before proceeding to the succeeding concepts (University of Southern California, 2012). This promotes an organized way to promote effective learning (Conford, 2006).

Laroza (2016) made a study on the validation and effectiveness of modules in Personality Development and Public Relations (PDPR). The results showed that modules are efficient and valid learning material as perceived by the respondents. Torrefranca (2017) and Mohajan (2017) used the same method of validation and found that modules contributed in the strudents'mastery.

Validation confirms the efficiency and authenticity of the learning materials as in the biological packet developed in this study to promote environmental protection awareness to Grade 9 students.

\section{Methodology}

Preparation of the Biological Learning Packets:

- Planning and Design phase. Lessons about Environmental Protection Awareness and its competencies based in the science curriculum provided by DepEd for grade 9 was utilized. The criteria in the evaluation of the learning packets were considered.

- Construction of the Module. Consolidation of the collected data, inclusion of the appropriate activities 
and construction of the evaluation using the pre-test and post-test.

- Permission to conduct the study. Upon completion of the required documents as stated in the curriculum guide of DepEd for grade 9, request for the issuance on the authorization to the concerned school principals and school heads to conduct the study.

Validation of the learning module. Fifty (50) Science teachers from different schools assessed the validity of the module which included Balian Integrated National High School, six (6) teachers; Lumban National High School, five (5) teachers; Pagsanjan (Integrated) National High School, eight (8) teachers; Pedro Guevara Memorial National High School, fifteen (15) teachers; Poten and Eliseo M. Quesada Memorial National High School, ten (10) teachers; and San Juan National High School, six (6) teachers.

Distribution and utilization of the learning module. The module was utilized by one hundred (100) Grade 9 students from Lumban National High School:

- Pre-test. All students took the fifty (50) item multiple choice test questions based fom the learning competencies.

- Actual use of the learning module. The module was utilized for the 10 days lessons.

- Post-test. At the end of the lesson,all students took the post-test which was identical to the pre-test.

- Treatment and analysis of Data. The data collected was subjected to the appropriate statistical treatment followed by the interpretation of the results and findings.

\section{Results and discussion}

The level of acceptability of the biological packets of learning in environmental awareness and protection as assessed by the teacher respondents in terms of its objectives, content, activities and evaluation.

As stated in the questionnaire the objectives are clear and easy to understand with the highest $(M=4.64$, $S D=0.48$ ). The objectives also expressed knowledge and skill needed to be developed with the students corresponds with a $(M=4.48, S D=0.57)$. This implies that the components of the Biological Packets in terms of objectives were Highly Acceptable and it is anchored on the learning competencies of the K-12 curriculum. All of the respondents strongly agree that the biological packet was highly acceptable in terms of objectives.

Table 1. Level of Acceptability of the Biological Packets of Learning in Environmental Awareness and Protection in terms of Objectives

\begin{tabular}{lccc}
\hline \multicolumn{1}{c}{ Statements } & Mean & $\begin{array}{c}\text { Standard } \\
\text { Deviation }\end{array}$ & Remarks \\
\hline $\begin{array}{l}\text { Are clearly stated and can easily understand } \\
\text { Are specific and attainable }\end{array}$ & 4.64 & 0.48 & Strongly Agree \\
$\begin{array}{l}\text { Expresses the knowledge and skills needed to be } \\
\text { developed }\end{array}$ & 4.56 & 0.50 & Strongly Agree \\
$\begin{array}{l}\text { Are based on the Grade 9 Learning Competencies } \\
\text { in the K to 12 Curriculum }\end{array}$ & 4.56 & 0.57 & Strongly Agree \\
$\begin{array}{l}\text { Are related to the discussion and exercises in the } \\
\text { supplementary material }\end{array}$ & 4.50 & 0.50 & Strongly Agree \\
$\quad$ Weighted Mean & 4.55 & 0.50 & Strongly Agree \\
& & & Highly Acceptable \\
\hline
\end{tabular}


It was supported by the studies made by Mahajan and Singh (2017) that objectives must serve as a navigating tool that directs the lesson towards its way without getting lost in the system. Kapur (2018) and Butcheer et al. (2009) recommended to formulate objectives based on the current needs of the learners.

Table 2. Level of Acceptability of the Biological Packets of Learning in Environmental Awareness and Protection in terms of Content

\begin{tabular}{|c|c|c|c|}
\hline Statement & Mean & $\begin{array}{c}\text { Standard } \\
\text { Deviatio } \\
\mathrm{n} \\
\end{array}$ & $\begin{array}{c}\text { Verbal } \\
\text { Interpretation }\end{array}$ \\
\hline $\begin{array}{c}\text { Are associated and appropriate to the lesson or concept } \\
\text { being learnt }\end{array}$ & 4.48 & 0.50 & Strongly Agree \\
\hline Engage and motivate learners & 4.40 & 0.63 & Strongly Agree \\
\hline Are interactive and interesting & 4.44 & 0.64 & Strongly Agree \\
\hline Present ideas in a comprehensive language & 4.32 & 0.47 & Strongly Agree \\
\hline Are sufficient to support learning & 4.48 & 0.50 & Strongly Agree \\
\hline Are appropriate for the learners' level of comprehension & 4.52 & 0.50 & Strongly Agree \\
\hline Are parallel with the objectives and activities & 4.60 & 0.49 & Strongly Agree \\
\hline $\begin{array}{c}\text { Contribute to the acquisition of concepts, understanding } \\
\text { and skills in biology }\end{array}$ & 4.52 & 0.50 & Strongly Agree \\
\hline Provide a range of learners' interest and preferences & 4.56 & 0.57 & Strongly Agree \\
\hline $\begin{array}{l}\text { Are sufficient to allow the learners to learn } \\
\text { independently }\end{array}$ & 4.52 & 0.64 & Strongly Agree \\
\hline Weighted Mean & 4.48 & 0.54 & Highly Acceptable \\
\hline
\end{tabular}

Table 2 shows the rating accorded by the respondents to the component of the biological packets of learning in environmental awareness in terms of its content. The content of the module pertains to the video presentations and the discussion. As seen in the table contents are parallel with the objectives and activities which is important to measure the students' outcome and gain the highest $(\mathrm{M}=4.60, \mathrm{SD}=0.49)^{\prime}$ ' $(\mathrm{M}=4.48$, $\mathrm{SD}=0.57)$ were indicated in statement number 4, "Present ideas in a comprehensive language". The weighted $(\mathrm{M}=4.48, \mathrm{SD}=0.54)$ characterized that respondents strongly agree that the content of biological packet was highly acceptable. It denotes that the videos selected for the lesson were associated and appropriate to the concept being learned. The discussions in the developed module are appropriate with the level of comprehension of the learners and contribute to the acquisition of concepts.

The findings were in compliance with DepEd Order No. 78, s. 2010 regarding the utilization multimedia technologies such as video presentation to improve the teaching-learning process and cater the challenges of the 21st century. Mendoza et al., (2015), Arias (2015), Beal (2012) stated that video presentations and multimedia technologies are effective instruments in improving the students' ICT capabilities because these motivate the learners to generate a unique perspective for their learning experiences. 
Table 3. Level of Acceptability of the Biological Packets of Learning in Environmental Awareness and Protection in terms of Activities

\begin{tabular}{|c|c|c|c|}
\hline Statement & Mean & $\begin{array}{l}\text { Standard } \\
\text { Deviation }\end{array}$ & Remarks \\
\hline $\begin{array}{l}\text { 1. Encourage creativity, higher order thinking, } \\
\text { and problem-solving }\end{array}$ & 4.60 & 0.49 & Strongly Agree \\
\hline 2. Motivate and engage the learners & 4.60 & 0.63 & Strongly Agree \\
\hline 3. Presented sequentially in order of difficulty & 4.32 & 0.63 & Strongly Agree \\
\hline 4. Are sufficient to support learning & 4.20 & 0.75 & Agree \\
\hline $\begin{array}{l}\text { 5. Realistic, appropriate and can be performed } \\
\text { with the resources available to the learners }\end{array}$ & 4.44 & 0.57 & Strongly Agree \\
\hline Weighted Mean & 4.43 & 0.62 & Highly Acceptable \\
\hline
\end{tabular}

Table 3 reveals the rating in viewed by the respondents to the component of the biological packets of learning in environmental awareness in terms of its activities. The highest were indicated in statement $1(M=$ 4.60, $\mathrm{SD}=0.49)$. The lowest $(\mathrm{M}=4.20, \mathrm{SD}=0.75)$ were indicated in statement number 4 . Table 3 reveals that the activities in the module motivate and engage learners, encourage creativity and higher order thinking skills.

Further, Yong (2018) and Rennick-Egglestone (2015) suggested that all the materials and activities for learning can be provided to the learners provided there is a regular follow up and monitoring in the students' progress that is helpful in the teaching-learning process.

The rating given by the respondents to the component of the biological packets of learning in environmental awareness in terms of its evaluation. All of the respondents rated the given learning packets as highly acceptable since the respondents strongly agree that the evaluation is congruent with the objectives given the $(M=4,60, S D=0,49)$. The $(M=4.36, S D=0.62)$ were indicated in statement number 5. This implies that the components of the material in terms of evaluation were easy to understand, relevant and appropriate for learning and thought provoking that make highly acceptable on the respondents $(\mathrm{M}=4.50, \mathrm{SD}=0.56)$.

The findings of Butcher et al. (2009) and Garantuza (2016) affirm that an effective evaluation has to be carefully planned at the beginning of the course to determine the level of understanding of students.

The rating given by the respondents to the teachers' material validation in terms of its usability. Most of the respondents strongly agree that the material was useful since it offers various activities that can be easily achieved through group effort with the $(M=4.52, S D=0.50)$. The lowest $(M=4.40, S D=0.66)$ was indicated in statement number 2, "Contains lessons that are responsive to the target learners' scientific skills". The data implies that the developed module provides learning task that can be easily achieved by the target learners.

This was confirmed by Alonso-Ríos et. al. (2009), Bevana, Kirakowski and Maissela (2015) and defined usability as the degree to which the learning material can achieve its specific goals and can be applied in the real world.

The achievement of the learning targets is an important element of effective instruction as stated by Alles et al., (2017). This will allow students to understand well the content, the procedures, and their own learning (Canonigo, 2017) and (Marbach-Ad et al., 2016). 
Table 4. Composite table on the Level of Acceptability of the Biological Packets

\begin{tabular}{cccc}
\hline Component/Characteristics & Mean & SD & Verbal Interpretation \\
\hline Objectives & 4.55 & 0.51 & Highly Acceptable \\
Content & 4.48 & 0.54 & Highly Acceptable \\
Activities & 4.43 & 0.62 & Highly Acceptable \\
Evaluation & 4.50 & 0.56 & Highly Acceptable \\
Usability & 4.46 & 0.57 & Highly Acceptable \\
Clarity & 4.56 & 0.54 & Highly Acceptable \\
Usefulness & 4.54 & 0.56 & Highly Acceptable \\
Weighted Mean & 4.50 & 0.56 & Highly Acceptable \\
\hline
\end{tabular}

Table 4 shows the composite result on the level of acceptability of the biological packets in terms of characteristic/component. All the given characteristics were rated highly acceptable. It connotes that the developed module is a usable, clear and useful tool in creating awareness among learners that may leads to the protection of the environment. It is a comprehensive, motivating, sequential and realistic learning material appropriate for the 21 st century learners. In the assessment made by the Science teachers it reflected that biological packets is a valid material for the teaching-learning process.

Table 5. Level of Students' Performance in terms of Pre-test and Post-test

\begin{tabular}{cccc}
\hline Test & Mean & $\begin{array}{c}\text { Standard } \\
\text { Deviation }\end{array}$ & $\begin{array}{c}\text { Verbal } \\
\text { Interpretation }\end{array}$ \\
\hline Pre-test & 7.39 & 1.62 & Fair \\
Post-test & 18.85 & 2.66 & Very Satisfactory \\
\hline
\end{tabular}

The pre-test $(\mathrm{M}=7.39, \mathrm{SD}=1.62)$ was interpreted as Fair and the post-test $(\mathrm{M}=18.85, \mathrm{SD}=2.66)$ was interpreted as Very Satisfactory. The data clearly shows the improvement in the students' performance after utilizing the developed module. This implies that the developed module was an effective learning tool since it enhanced the level of students' performance.

Torrefranca (2017) and Delucchi (2014) in their findings showed that through the use of pre-test and posttest design a significant change was observed after the use of instructional modules; that pretest-posttest tool once put into practice can be used to improve the method of teaching.

\section{Conclusion}

Based on the findings, the developed biological learning packets was highly acceptable and was found to be an effective teaching tool. Finally, results of the study suggest to make use of the module which is effective in the enhancement of the students environmental protection awareness.

\section{Recommendations}

In view of the findings and conclusion stated in the study, the following recommendations are proposed; (1) The Science teachers may use the developed and assessed Biological Packets of Learning in Environmental Awareness and Protection in teaching grade 9. (2) The local community and environmental groups may use the module in creating environmental awareness and protection. (3) Future researchers can 
further enhance and validate the biological packets of learning in environmental awareness and protection, provided the results of evaluation be taken into consideration.

\section{References}

Alles, M., Seidel, T., and Gröschner, A. (2017). Toward Better Goal Clarity in Instruction: How Focus On Content, Social Exchange and Active Learning Supports Teachers in Improving Dialogic Teaching Practices. International Education Studies, 11-24.

Alonso-Ríos, D., Vázquez-García, A., Mosqueira-Rey, E. and Moret-Bonillo, V. (2009). Usability: A Critical Analysis and a Taxonomy. International Journal, 1-19.

Arias, P. (2015). ICT Integration - A Breakthrough In Teaching. Malaybalay City: DepEd Division of Malaybalay.

Beal, J. (2012). Reflective Learning for Students. Retrieved from University of Sheffield: https://www.sheffield.ac.uk/lets/toolkit/learning/reflective

Bevana, N., Kirakowski, J., and Maissela, J. (2015). What is Usability? Proceedings of the $4^{\text {th }}$ International Conference on HCI. Cork, Ireland.

Butcher, C., Davies, C. and Highton, M. (2009). Designing Learning: From Module Outline to Effective Teaching. London and New York: Blackwell Publishing Ltd.

Canonigo, A. M. (2017). Principles of High Quality Assessment. Retrieved from https://www.google.com/search?q=clarity+of+learning+instument +pdf\&oq=clarity+of+learning+instument+pdf\&aqs=chrome..69i57.23353j0j7\&sourceid=chrome\& ie=U TF-8\#

Climate Reality Project. (2016, January 19). How is Climate Change Affecting the Philippines? Retrieved from Climate Reality Project: https://www.climaterealityproject.org/blog/how-climate-change- affecting-philippines

Conford, I. R. (2006). Ensuring Effective Learning from Modular Courses; A Cognitive. Journal of Vocational Education and Training, 237.

Datukon, S. A. (2016). Top 5 Environmental Problems in the Philippines. Philippines: PSST Philippines.

Delucchi, M. (2014). Measuring Student Learning in Social Statistics: A Pretest- Posttest Study of Knowledge Gain, Teaching Sociology. American Sociological Association, 231- 239.

DepEd Order No. 78, s. 2010. Guidelines on the Implementation of the DepEd Computerization Program (DCP). June 10, 2010

De Regla, E. N. (2015). The Relationship of Environmental Awareness in Selected Topics in Science Academic Performance of Education Students in Bulacan State University-Bustos Campus, Philippines. International Journal of Scientific and Research Publications, 1-5.

Garantuza, E. A. (2016). Module in Teaching Listening. Unpublished Master's Thesis. Santa Cruz, Laguna: LSPU Sta. Cruz Campus.

Garcia, E. C. and Luansing, B. (2016). Environmental Awareness Among Select Graduating College in Region IVA. LPU-Laguna Journal of Multidisciplinary Research, 1-10.

Kapur, R. (2018). Formulation of Objectives in Curriculum Development. New Delhi: University of Delhi.

Laroza, R. D. (2016). Validation and Effectiveness of Modules in Personality Development and Public Relations. International Journal of Scientific and Research Publications, 1-2.

Mahajan, M. and Singh, M. (2017). Importance and Benefits of Learning Outcomes. Journal Of Humanities And Social Science (IOSR-JHSS), 65-67.

Marbach-Ad, G., McGinnis, J., Pease, R., Dai, A., and Schalk, K. (2016). Clarity in Teaching and Active Learning in Undergraduate Microbiology Course for Non-Majors. University of Maryland, College Park, 1-7.

Medallon, M. C. and Gallardo, M. (2014). Environmental Awareness Campaign: The Change It Brings. Asia Pacific Journal of Multidisciplinary Research, 2(1), 115-120.

Maseret, D. (2016). Promoting Environmental Awareness of Youth through School Environmental Clubs: A Case Study in Debre Tabor University, Ethiopia. International Affairs and Global Strategy, 14-20.

Mendoza, G., Caranto, L., David, J. (2015). Effectiveness of Video Presentation to Students' Learning. International Journal of Nursing Science, 81-86.

Mohajan, H. K. (2017). Two Criteria for Good Measurements in Research: Validity and Reliability. Annals of Spiru Haret University, $1-32$.

Rennick-Egglestone, S. (2015, September 24). This is why traditional lectures are better than wideo. Retrieved from Times Higher Education: https://www.timeshighereducation.com/blog/why- traditional-lectures-arebetter-watching-vide

Takala, M. (2007). Environmental Awareness and Human Activity. International Journal of Psychology, 23.

Torrefranca, E. C. (2017). Development and Validation of Instructional Modules on Rational Expressions and Variations. The Normal Lights, 44-45. 
University of Southern California. (2012). Learning Modules. Retrieved from https://blackboardhelp.usc.edu/course-content/adding-content-and-resources/learning-

Yong, S. W. (2018). Kepner-Tregoe. Retrieved from KT Kepner-Tregoe: https://www.kepnerstop-at-the-classroom-door/\#
Blackboard Help for Faculty: modules/

tregoe.com/blog/learning-does-not- 